\title{
Própolis e cera vegetal na conservação de abacate 'Hass'
}

\section{Propolis and vegetable wax in the conservation of Hass avocado}

\author{
Érica Regina Daiuto ${ }^{1 *}$; Philipp Herbst Minarelli; \\ Rogério Lopes Vieites ${ }^{3}$; Ricardo de Oliveira Orsi ${ }^{4}$
}

\section{Resumo}

Objetivou-se neste trabalho avaliar a aplicação de própolis e cera vegetal na qualidade pós-colheita do abacate 'Hass'. Os frutos selecionados foram submetidos aos tratamentos (1) sem cera e sem própolis, (2) com cera vegetal, (3) extrato alcoólico de própolis $100 \%$, (4) cera e etanol 70\%, (5) extrato alcoólico de própolis $2 \%$ e cera, (6) extrato alcoólico de própolis $4 \%$ e cera, (7) extrato alcoólico de própolis $6 \%$ e cera, (8) extrato alcoólico de própolis $8 \%$ e cera e (9) extrato alcoólico de própolis $10 \%$ e cera. Os frutos foram mantidos sob refrigeração $\left(10 \pm 1{ }^{\circ} \mathrm{C}\right.$ e $90 \pm 5 \%$ umidade relativa), sendo avaliados a cada três dias durante 15 dias e mais 3 dias de simulação de comercialização em temperatura ambiente $\left(23 \pm 1{ }^{\circ} \mathrm{C}\right.$ e $18 \%$ umidade relativa). Os parâmetros de avaliação foram a perda de massa, atividade respiratória, pH, firmeza, acidez titulável (AT), sólidos solúveis (SS) e ratio. Os resultados de perda de massa, atividade respiratória e firmeza foram os mais significativos para mostrando diferença entre os tratamentos. Frutos de abacate 'Hass' submetidos à aplicação de própolis associado a cera vegetal apresentam menor perda massa, produção de $\mathrm{CO}_{2}$ e firmeza em relação aos frutos controle. Os frutos do tratamento com extrato alcoólico de própolis $2 \%$ e cera apresentaram os resultados mais promissores.

Palavras-chave: Persea americana Mill., refrigeração, atmosfera modificada, firmeza, pós-colheita

\begin{abstract}
The aim of this work was to evaluate the quality of Hass avocado submitted to application of propolis and vegetable wax. The selected fruits were submitted to the treatments (1) without wax and without propolis, (2) with vegetable wax, (3) propolis alcoholic extract $100 \%$, (4) wax and etanol $70 \%$, (5) propolis alcoholic extract $2 \%$ and wax, (6) propolis alcoholic extract $4 \%$ and wax, (7) propolis alcoholic extract $6 \%$ and wax, (8) propolis alcoholic extract $8 \%$ and wax, and (9) propolis alcoholic extract $10 \%$ and wax. The fruits were maintained under refrigeration $\left(10 \pm 1{ }^{\circ} \mathrm{C}\right.$ and $90 \pm 5 \%$ relative humidity), being appraised every three days for 15 days and more 3 days of commercialization simulation at room temperature $\left(23 \pm 1{ }^{\circ} \mathrm{C}\right.$ and $18 \%$ relative humidity).The evaluation parameters were the weight loss, respiratory activity, $\mathrm{pH}$, firmness, tritable acidity (AT), soluble solids (SS), and ratio. The results of weigth loss, respiratory activity and firmness were the most significant to show the difference among the treatments. 'Hass' avocado fruits submitted the application of propolis associated the vegetable wax present smaller weight loss, $\mathrm{CO}_{2}$ production and firmness in relation to the control fruits. The fruits of the treatment with propolis alcoholic extract $2 \%$ and wax presented the most promising results.
\end{abstract}

Key words: Persea americana Mill., refrigeration, modified atmosphere, firmness, postharvest

1 Pós doutoranda no curso de Horticultura na Faculdade de Ciências Agronômicas da Universidade Estadual Paulista "Julio de Mesquita Filho", UNESP, Botucatu, SP. E-mail: erdaiuto@uol.com.br

2 Discente de graduação no curso de Engenharia Agronômica na UNESP, Botucatu, SP. E-mail: hminareli@hotmail.com

3 Prof. Titular do Dept ${ }^{\circ}$ de Gestão e Tecnologia de Alimentos, UNESP, Botucatu, SP. E-mail: vieites@fca.unesp.br

4 Prof. Dr. do Dept ${ }^{\circ}$ de Produção Animal na UNESP, Botucatu, SP. E-mail: orsi@fmvz.unesp.br

Autor para correspondência

Recebido para publicação 06/12/11 Aprovado em 08/06/12 


\section{Introdução}

O abacate (Persea americana Mill) é fruto climatérico cujo amadurecimento ocorre poucos dias após a colheita (HARDENBURG; WATADA; WANG, 1986, SEYMOUR; TUCKER, 1993). Abacates 'Hass' têm sido valorizados no mercado devido aceitação no exterior e aumento do consumo no Brasil. Os frutos desta variedade apresentam calibre menor em relação àqueles comumente comercializados no mercado interno e alto teor de lipídios com alto teor de ácidos graxos insaturados, sendo portanto relacionado a prevenção de doenças cardiovasculares.

Dentre os métodos que podem ser empregados para ampliar a vida de prateleira das frutas em geral, inclui-se o uso de atmosfera modificada, que pode ser pelo acondicionamento das frutas em filmes plástico ou pelo recobrimento com ceras especiais. Estes tratamentos modificam o ar circundante e interno da fruta, reduzindo os níveis de $\mathrm{O}_{2}$ e aumentando os níveis de $\mathrm{CO}_{2}$. Conseqüentemente, reduzem o metabolismo do vegetal, retardando a senescência (CHITARRA; CHITARRA, 2005; GORRIS; PEPPLENBOS, 1992). As ceras não permitem a perda de umidade dos frutos por serem materiais hidrofóbicos. Portando, o uso de ceras tem o objetivo de reduzir a perda de massa (umidade), consequentemente, o amolecimentoe a desidratação. Além disso, a aplicação de cera também tem por finalidade dar maior brilho à fruta, melhorando a qualidade visual da mesma (KAPLAN, 1986). Joyce, Shorter e Jones (1995) relataram que abacates 'Hass' armazenados à temperatura constante de $22{ }^{\circ} \mathrm{C}$ apresentaram uma perda de peso diária de $0,99 \%$, sendo que quando os mesmos foram tratados com a cera produzida pela firma Colin Campbell Chemistry, a perda de peso diária foi de $0,51 \%$.

Atualmente, a incorporação da própolis em filmes comestíveis tem sido avaliada. Juliano, Pala e Cossu (2007) mostrou que filmes poliméricos contendo própolis apresentam aplicações potenciais não só na indústria farmacêutica, mas também na agricultura e indústria alimentar. Uma vez que tem um sabor e odor desagradável, seu encapsulamento em filmes comestíveis para ser aplicado na conservação de alimentos pode representar uma forma alternativa de consumir a própolis. Além disso, Pastor et al. (2010) menciona que os compostos hidrofóbicos da própolis contribuem para melhorar algumas propriedades de filmes de polímeros, tais como o vapor de água de barreira. Tal característica deve ser considerada benéfica se permitir redução de perda de massa por transpiração, que ocorre nos frutos durante $\mathrm{o}$ armazenamento. A própolis e seus extratos agem também como antimicrobianos naturais (KAMEYAMA et al., 2008). A própolis ainda pode ajudar em questões ambientais e de saúde, quando usada em substituição a fungicidas sintéticos no controle de fungos na conservação pós-colheita de produtos vegetais (TRIPATHI; DUBEY, 2004).

Diante das características aqui elucidadas, a própolis possui um grande potencial quanto ao seu uso nas técnicas de conservação de produtos de origem vegetal e sua adição à cera vegetal, em concentrações relativamente pequenas, aplicada em abacate 'Hass' poderá resultar no aumento da vida de prateleira dos frutos. Portanto, o objetivo desta pesquisa foi avaliar a aplicação do própolis e cera vegetal na qualidade pós colheita do abacate 'Hass'.

\section{Matérias e Métodos}

Abacates 'Hass' foram fornecidos pela empresa Jaguacy, localizada em Bauru/SP-Brasil, cujas coordenadas geográficas são: latitude $22^{\circ} 19^{\prime} 18^{\prime \prime}$ S, longitude $49^{\circ} 04^{\prime} 13^{\prime \prime} \mathrm{W}$ e $526 \mathrm{~m}$ de altitude. Os frutos de abacate cuidadosamente colhidos no ponto de maturação fisiológica e de acordo com o teor de óleo $(21,6 \%)$ foram selecionados, lavados em água corrente e sanitizados, sendo imersos em solução clorada (1\%) durante 20 minutos. Os frutos foram acondicionados em bandejas plásticas para serem submetidos aos seguintes tratamentos: sem cera e sem própolis (T1), com cera vegetal (T2), extrato 
alcoólico de própolis 100\% (T3), cera e etanol 70\% (T4), extrato alcoólico de própolis $2 \%$ e cera (T5), alcoólico de própolis 4\% e cera (T6), alcoólico de própolis $6 \%$ e cera (T7), alcoólico de própolis $8 \%$ e cera (T8) e alcoólico de própolis 10\% e cera (T9). A cera utilizada no experimento foi a Waterwax-UE (Composição: 18,0\%p/p polietileno oxidado E-914, goma laca E-904 e 2,\%p/p hidróxido amônico)

Os frutos foram mantidos sob refrigeração (10 \pm $1{ }^{\circ} \mathrm{C}$ e $90 \pm 5 \%$ UR), sendo avaliados a cada três dias durante 15 dias e mais 3 dias de simulação de comercialização em temperatura ambiente $(23 \pm 1$ ${ }^{\circ} \mathrm{C}$ e $18 \%$ UR). Os frutos foram avaliados quanto a perda de massa, atividade respiratória, $\mathrm{pH}$, acidez total titulável, sólidos solúveis e firmeza.

A perda de massa fresca foi determinada pela pesagem dos frutos em balança analítica, considerando a massa inicial de cada amostra, com os resultados expressos em percentagem.

A respiração foi avaliada pela liberação de $\mathrm{CO}_{2}$ em cada embalagem, de acordo com metodologia adaptada de Bleinroth, Zuchini e Pompeo. (1976), utilizando-se para isso solução de hidróxido de bário saturado e solução de hidróxido de potássio 0,1 N. Para tanto, foi utilizada a seguinte fórmula: $\mathrm{TCO}_{2}=2,2\left(\mathrm{Vo}_{1} \mathrm{~V}_{1}\right) \cdot 10 / \mathrm{P} . \mathrm{T}$. Onde: $\mathrm{T} \mathrm{CO}_{2}=$ taxa de respiração $\left(\mathrm{mL}\right.$ de $\left.\mathrm{CO}_{2} \cdot \mathrm{Kg}^{-1} \cdot \mathrm{h}^{-1}\right)$; $\mathrm{Vo}=$ volume gasto de $\mathrm{HCl}$ para titulação de hidróxido de potássio padrão antes da absorção de $\mathrm{CO}_{2}(\mathrm{~mL}) ; \mathrm{V}_{1}=$ volume gasto de $\mathrm{HCl}$ para titulação de hidróxido de potássio após a absorção de $\mathrm{CO}_{2}$ da respiração $(\mathrm{mL}) ; \mathrm{P}=$ massa dos frutos; $\mathrm{T}=$ tempo da respiração; $2,2=$ inerente ao equivalente de $\mathrm{CO}_{2}(44 / 2)$, multiplicado pela concentração do ácido clorídrico; $10=$ ajuste para o total de hidróxido de potássio utilizado.

Os teores de sólidos solúveis (SS), acidez titulável (AT) e pH, foram determinados segundo IAL (2008). $\mathrm{O}$ pH foi obtido por potenciometria utilizando-se o potenciômetro ANALYSER - modelo pH300. O teor de sólidos solúveis foi determinado em ${ }^{\circ}$ Brix a $20^{\circ} \mathrm{C}$ no refratômetro digital tipo Palette PR - 32, marca ATAGO, com compensação de temperatura automática. a $20^{\circ} \mathrm{C}$. Foi determinado também o ratio pela relação entre o teor de sólidos solúveis e acidez titulável (IAL, 2008).

A avaliação da firmeza foi feita utilizando-se texturômetro STEVENS - LFRA Texture Analyser, com a distância de penetração de $20 \mathrm{~mm}$, velocidade de 2,0 $\mathrm{mm} \cdot \mathrm{s}^{-1}$ e ponta de prova TA 9/1000. Os resultados foram apresentados em g.força ${ }^{-1}$. Foram realizadas 5 leituras em cada uma das 3 repetições em todos os tratamentos.

Os dados foram avaliados pela análise de variância no delineamento inteiramente ao acaso no esquema fatorial, com três repetições, seguida do teste de Tukey para comparação múltipla entre as médias. O nível de significância utilizado foi de 5\%, utilizando-se o programa estatístico SAS (STATISTICAL ANALYSIS SYSTEM, 2003). O esquema fatorial foi $8 \times 7$, sendo o primeiro fator composto pelos tratamentos realizados aos frutos com extrato de própolis e cera vegetal, e o segundo fator consistiu de 7 tempos de avaliação $(0,3,6,9$, 12,15 e 18 dias)

\section{Resultados e Discussões}

A perda de massa fresca dos frutos (Figura 1) foi crescente para todos os tratamentos, sendo superior para o tratamento controle (sem própolis ou cera). Já os tratamentos com aplicação de cera e etanol $70 \%$ (T4) e extrato alcoólico de própolis 2\% (T5) apresentaram perdas significativamente menores em relação ao controle. Observa-se que apenas com a aplicação da cera a perda de massa é reduzida em relação ao controle. Já os tratamentos onde se utilizou extrato alcoólico houve menor perda de massa do que quando se utiliza somente a cera, sendo que a menor concentração do extrato alcoólico de própolis teve melhor resultado entre as várias concentrações. O mesmo foi observado para o tratamento em que se utilizou apenas o extrato de própolis alcoólico (T3), sendo a perda de massa para estes frutos inferior ao controle, mas superior ao T2 e T4. Com base nos vários tratamentos realizados 
pressupõe-se que a adição do álcool à cera alterou seu comportamento.

Para a maioria dos produtos hortícolas frescos, a máxima perda de massa fresca tolerada para o não aparecimento de murcha e/ou enrugamento da superfície oscila entre 5 e 10\% (FINGER; VIEIRA,
2002) e produtos perecíveis como o abacate mesmo quando colocados em condições ideais, sofrem alguma perda de peso durante o armazenamento devido ao efeito combinado da respiração e da transpiração (CHITARRA; CHITARRA, 2005).

Figura 1. Perda de massa (\%) de abacate 'Hass' submetido à aplicação de própolis e cera vegetal.

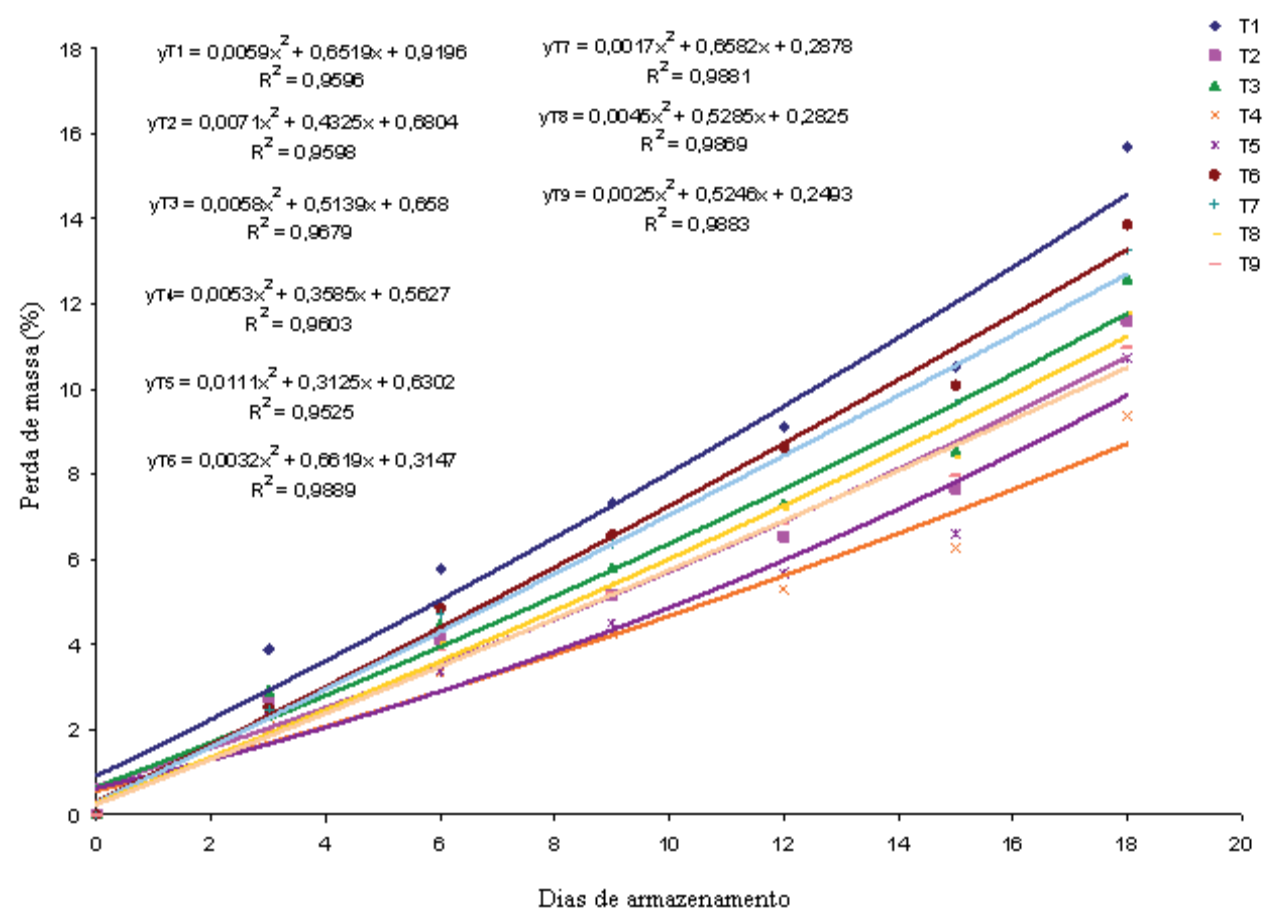

Legenda: Sem cera e sem própolis (T1), com cera vegetal (T2), extrato alcoólico de própolis 100\% (T3), cera e etanol $70 \%$ (T4), extrato alcoólico de própolis $2 \%$ e cera (T5), extrato alcoólico de própolis $4 \%$ e cera (T6), extrato alcoólico de própolis $6 \%$ e cera (T7), extrato alcoólico de própolis $8 \%$ e cera (T8) e extrato alcoólico de própolis $10 \%$ e cera (T9)

Fonte: Elaboração dos autores.

Observou-se para taxa respiratória (Figura 2), o comportamento climatérico já descrito para o abacate (SEYMOUR; TUCKER, 1993); DAIUTO; TREMOCOLDI; VIEITES, 2010; DAIUTO et al., 2010). Para maioria dos tratamentos realizados (T1, T2, T3, T4, T7, T8) o pico respiratório ocorreu aproximadamente no $9^{\circ}$ dia de armazenamento, concordando com Daiuto et al. (2010) em abacate 'Hass' que avaliou os frutos submetidos a diferentes tratamentos físicos (hidrotermia, radiação gama e
UV-C) em temperatura ambiente e sob refrigeração, constatando pico respiratório no mesmo momento. Nos tratamentos com frutos de pico no $9^{\circ}$ dia de armazenamento, observou-se diferenças entre os mesmos pela intensidade da taxa de respiração. Os frutos dos tratamentos com extrato alcoólico de própolis $4 \%$ e cera (T6), e extrato alcoólico de própolis $10 \%$ e cera (T9) apresentaram baixa produção de $\mathrm{CO}_{2}$, sendo observada uma elevação da intensidade somente no $15^{\circ}$ dia de armazenamento. 
Os frutos submetidos ao tratamento extrato alcoólico de própolis $2 \%$ e cera (T5) destacou-se por apresentar o pico respiratório mais tardio, $13^{\circ}$ dia de armazenamento, porém com produção de $\mathrm{CO}_{2}$ mais elevada neste momento. Assim como verificado para perda de massa, a adição de álcool à cera (T4) alterou o comportamento da cera em relação ao $\mathrm{T} 2$ ( apenas cera vegetal). A produção de $\mathrm{CO}_{2}$ foi mais elevada nos tratamentos T3 e T4 em relação ao T2.
Manolopoulou e Papadopoulou e Chitarra e Chitarra (2005) afirmam que a intensidade da taxa respiratória esta relacionada com a capacidade de armazenamento do produto, e que, quanto maior a taxa respiratória, menor é o tempo de armazenamento. Desta forma, para o parâmetro respiração, pressupõe-se para os frutos dos tratamentos 6 e 9, maior potencial de conservabilidade.

Figura 2. Atividade respiratória $\left(\mathrm{mL}\right.$ de $\left.\mathrm{CO}_{2} \cdot \mathrm{Kg}^{-1} \cdot \mathrm{h}^{-1}\right)$ de abacate 'Hass' submetido à aplicação de própolis e cera vegetal.

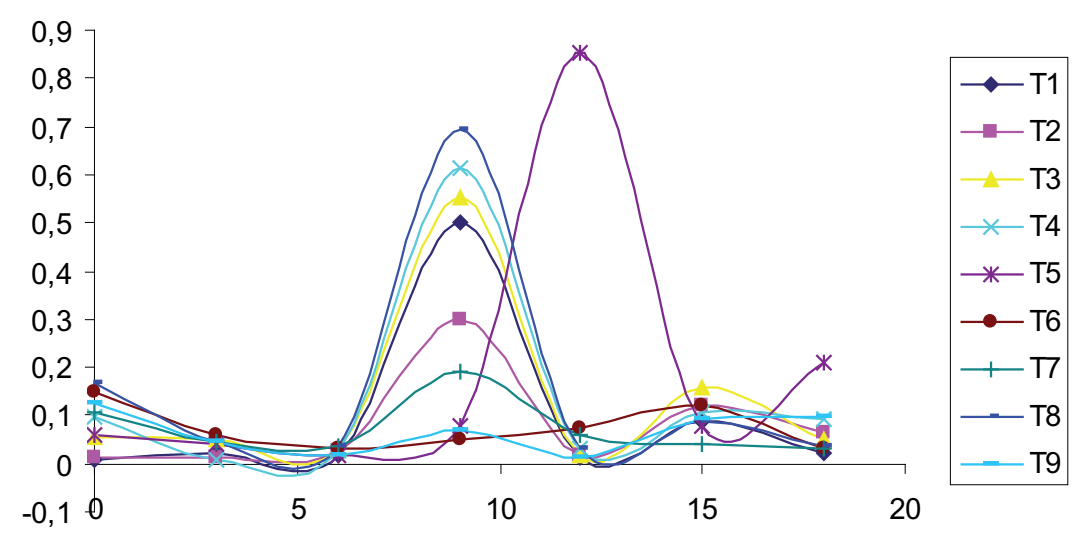

Legenda: Sem cera e sem própolis (T1), com cera vegetal (T2), extrato alcoólico de própolis $100 \%$ (T3), cera e etanol 70\% (T4), extrato alcoólico de própolis $2 \%$ e cera (T5), alcoólico de própolis 4\% e cera (T6), alcoólico de própolis $6 \%$ e cera (T7), alcoólico de própolis $8 \%$ e cera (T8) e alcoólico de própolis $10 \%$ e cera (T9)

Fonte: Elaboração dos autores.

Para os teores de acidez titulável (Tabela 1) houve efeito da interação tratamento e dia de armazenamento $(\mathrm{p}<0,001)$. Observou-se uma redução dos valores após o terceiro dia de armazenamento, com posterior elevação após o $12^{\circ}$ dia. Em todos os tratamentos os teores de acidez aumentaram após o $15^{\circ}$ dia, quando os frutos foram retirados do armazenamento refrigerado e submetidos a temperatura ambiente.

A redução da acidez é decorrência natural da evolução da maturação dos frutos, na qual os ácidos orgânicos são metabolizados na via respiratória e convertidos em moléculas não-ácidas (CHITARRA;
CHITARRA, 2005). Já o aumento da acidez pode ser decorrente de contaminação por microrganismos e uso de açúcares como substrato elevando a concentração de ácidos (PECH, 2002), no entanto, visualmente não foi observada contaminação dos frutos. Esse aumento, segundo Costa e Balbino (2002) deve-se à formação do ácido galacturônico no processo de degradação da parede celular processos que ocorrem durante o amadurecimento de frutos.

Como consequência do metabolismo respiratório climatérico, os teores de SS do abacate incrementaram ao longo do período experimental, 
atingindo valores máximos entre o $6^{\circ}$ e $12^{\circ}$ dia para os frutos controle, $12^{\circ}$ dia para o tratamento $2,9^{\circ}$ dia para os tratamentos $3,5,6,8$ e 9 e $15^{\circ}$ dia para os tratamentos 4 e 7 . A partir deste instante, prestandose como substrato energético para a transformação e sobrevivência pós-colheita. Observou-se redução nos teores de SS para quase todos os tratamentos após retirada do armazenamento refrigerado e manutenção por 3 dias sob temperatura ambiente, quando os frutos consumiram reserva de açúcares. O tratamento 7, manteve os valores mais elevados (Tabela 2).

O ratio é a relação SS/AT, sendo um parâmetro indicativo de amadurecimento e qualidade do fruto (CHITARRA; CHITARRA, 2005), e os resultados foram reflexo da variação no teor de SS e AT durante o armazenamento. Observou-se diferenças estatísticas durante o armazenamento com elevação da relação SS/AT ocorridas principalmente no pico climatérico dos frutos. A diferença entre tratamentos foi observada apenas nos dias 6, 9 e 12 de avaliação (Tabela 3).

Apesar da diferença estatística observada para os valores de $\mathrm{pH}$ entre tratamentos e dias de armazenamento (Tabela 4), as variações foram pequenas, sendo os valores encontrados normais para frutos de abacate. Daiuto et al. (2010) em abacate 'Hass' e Oliveira et al. (2000) em abacate 'Fuerte', encontraram estabilidade nos valores de $\mathrm{pH}$ durante o armazenamento.

Houve efeito da interação tratamento e dias de armazenamento $(\mathrm{p}<0,001)$ para firmeza (Tabela 5). Após o $3^{\circ}$ dia de armazenamento observou-se perda de firmeza para todos os tratamentos, com queda acentuada para o tratamento controle. Os frutos dos tratamentos 5 e 7 apresentaram a menor perda de firmeza neste momento, daqueles foram tratado apenas com cera vegetal. Os frutos do tratamento 5 foram os que mantiveram por mais tempo valores elevados de firmeza durante o período experimental (até o $6^{\circ}$ dia de armazenamento). Até o dia 6 os frutos apresentaram diferenças quanto à firmeza se destacando os tratamentos 4, 5 e 7. Após este período os frutos dos tratamentos se comportaram de maneira semelhante quanto a médias de cada tratamento para cada dia não variando estatisticamente entre si. O tratamento 5 apresentou uma firmeza do fruto superior quando comparada aos demais tratamentos durante toda a avaliação. Os tratamentos 4, 6 e 9 por apresentarem menor perda de firmeza durante a simulação de prateleira, mas foram os frutos do tratamento 5 que mantiveram os maiores valores de firmeza.

Vale destacar que visualmente não foi observada contaminação dos frutos por microorganismos, mesmo após a retirada destes do armazenamento refrigerado, destacando-se o aspecto externo dos frutos dos tratamentos com cera e própolis em relação ao controle. Nesta fase do projeto não foi realizada avaliação sensorial. No entanto, um grupo de 5 pessoas fez uma avaliação informal e de forma subjetiva dos frutos ao final do experimento. Não foi observada alterações no sabor da polpa em relação ao tratamento testemunha, no entanto, frutos dos tratamentos 8 e 9 apresentaram um aroma agradável e superior aos demais. 

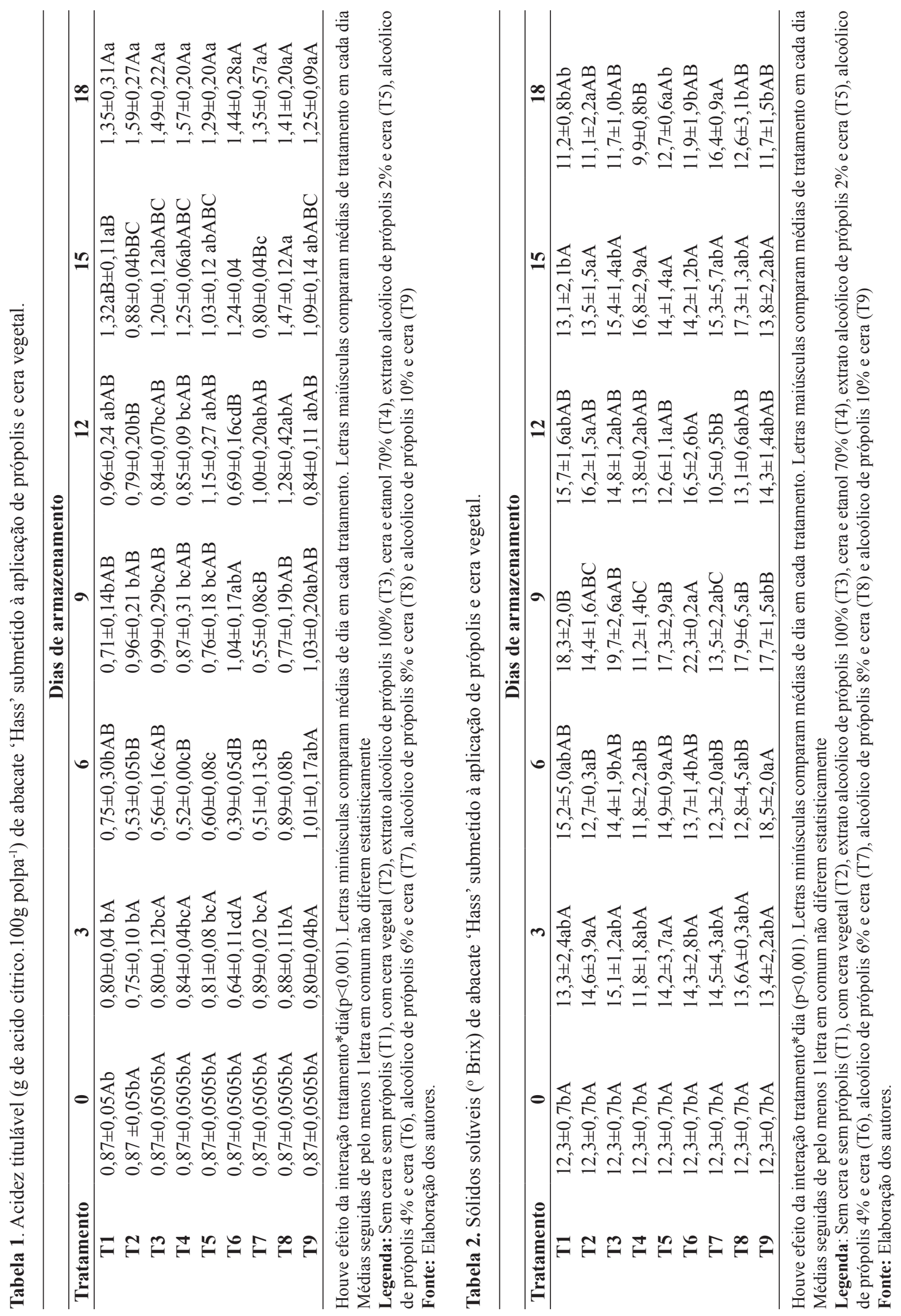


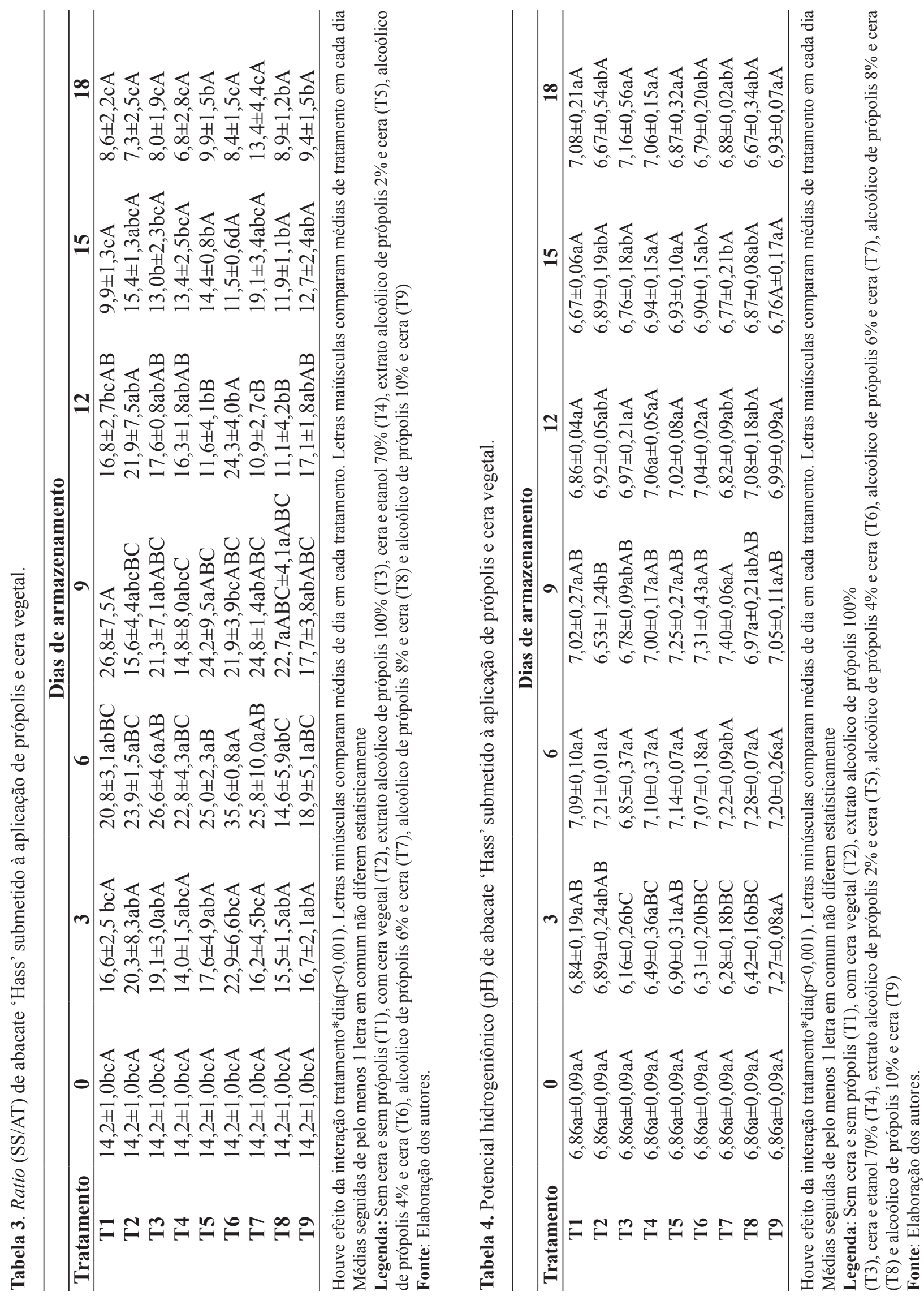




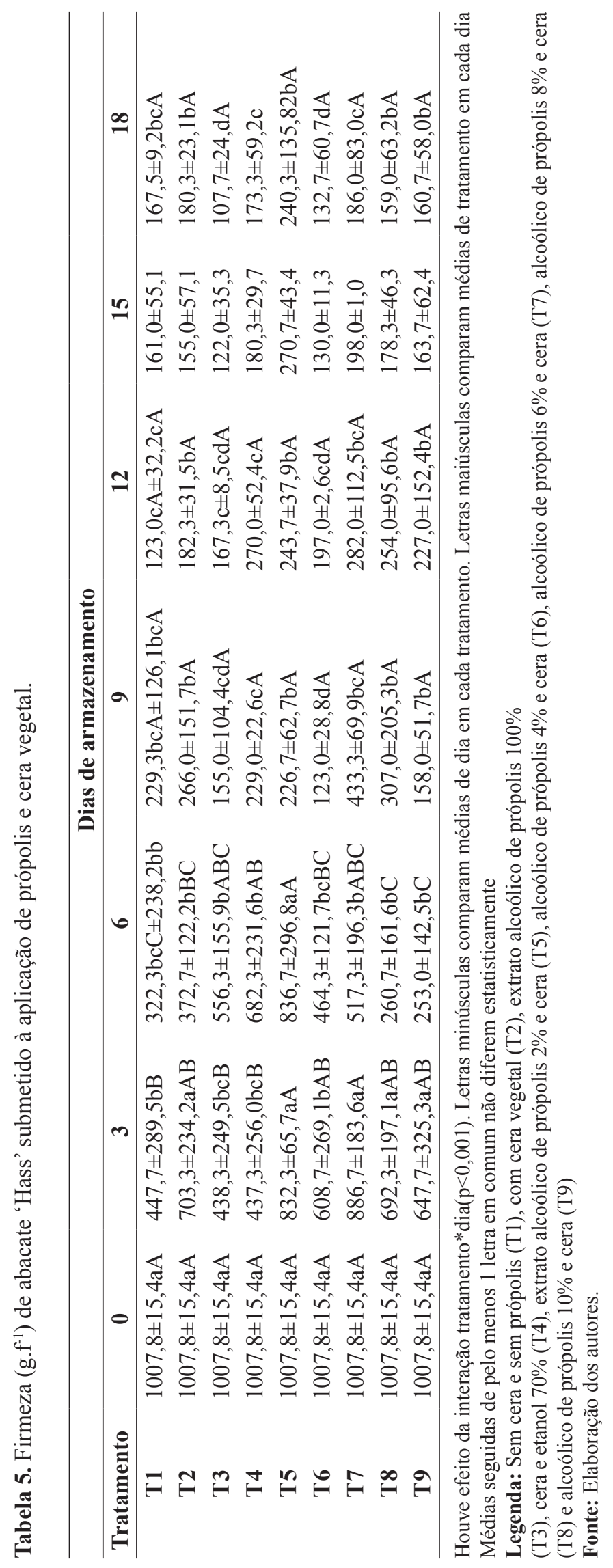




\section{Conclusões}

Frutos de abacate 'Hass' submetidos a aplicação de própolis associado a cera vegetal apresentam menor perda massa, produção de $\mathrm{CO}_{2}$ e firmeza em relação aos frutos controle. Os frutos tratados com extrato alcoólico de própolis $2 \%$ e cera (T5) apresentaram os melhores resultados para estes parâmetros. O aspecto visual dos frutos com aplicação de própolis e cera é favorável a comercialização dos frutos devido ao brilho observado na casca. O extrato aquoso de própolis deve ser avaliado, uma vez que a adição do álcool à cera vegetal modifica seu comportamento.

\section{Referências}

BLEINROTH, E. W.; ZUCHINI, A. G.; POMPEO, R. M. Determinação das características físicas e mecânicas de variedade de abacate e sua conservação pelo frio. Coletânea ITAL, Campinas, v. 7. n. 1, p. 29-81, 1976.

CHITARRA, M. I. F.; CHITARRA, A. B. Pós-colheita de frutos e hortaliças: fisiologia e manuseio. Lavras: Ed. UFLA, 2005. $785 \mathrm{p}$.

COSTA, A. F. S.; BALBINO, J. M. S. Características da fruta para exportação e normas de qualidade. In: FOLEGATTI, M. I. S.; MATSUURA, F. C. A. U. (Ed.). Mamão: pós-colheita. Brasília, DF: Embrapa Informação Tecnológica, 2002. p. 12-18. (Série Frutas do Brasil, 21).

DAIUTO, E. R.; TREMOCOLDI, M. A.; VIEITES, M. A. Conservação pós colheita de abacate 'hass' irradiado. Revista Iberoamericana de Tecnología Postcosecha, México, v. 10, n. 2, p. 94-100, 2010.

DAIUTO, E. R.;VIEITES, R. L.; TREMOCOLDI, M. A.; RUSSO, V. C. Taxa respiratória de abacate 'hass' submetido a diferentes tratamentos físicos. Revista Iberoamericana de Tecnología Postcosecha, México, v. 10, n. 2, p. 101-109, 2010.

FINGER, F. L.; VIEIRA, G. Controle da perda póscolheita de água em produtos hortícolas. Viçosa: UFV, 2002. $29 \mathrm{p}$.

GORRIS, L. G. M.; PEPPELENBOS, H. W. Modified atmosphere and vacuum packaging to extend the shelf life of respiring food products. Hort Technology, Alexandria, v. 2, n. 3, p. 303-309, 1992.
HARDENBURG, R. E.; WATADA, A. E.; WANG, C. Y. The comercial storage of fruits, vegetables, and florist and nursery stocks. Beltsville: USDA, 1986. $130 \mathrm{p}$.

INSTITUTO ADOLFO LUTZ - IAL. Métodos físicoquímicos para análise de alimentos. Coordenadores Odair Zenebon, Neus Sadocco Pascuet e Paulo Tiglea. São Paulo: Instituto Adolfo Lutz, 2008. p. 1020. Disponível em: <www.ial.sp.gov.br $>$. Acesso em: 06 jun. 2012.

JOYCE, D. C.; SHORTER, A. J.; JONES, P. N. Effect of delayedfilm wrapping and waxing on the shelf life of avocado fruit. Australian Journal of Experimental Agriculture, Melbourne, v. 35, p. 657-659, 1995.

JULIANO, C.; PALA, C. L.; COSSU, M. Preparation and characterization of polymeric films containing propolis. Journal of Drug Delivery Science and Technology, Paris, v. 17, n. 3, p. 177-181, 2007.

KAMEYAMA, O.; ABRÃO JÚNIOR, J.; TEIXEIRA, J. M. A.; ANDRADE, N. J.; MININ, V. P. R.; SOARES, L. S. Extrato de própolis na sanitização e conservação de cenoura. Revista Ceres, Viçosa, v. 55, n. 3, p. 218-223, 2008.

KAPLAN, H. J. Washing, waxing, and color-adding. In: WARDOWSKI, W. F.; NAGY, S.; GRIERSON, W. (Ed.). Fresh citrus fruit. New York: AVI, 1986. p. 379-395.

MANOLOPOULOU, H. P.; PAPADOPOULOU, P. A study of respiratory and physico-chemical changes of four kiwi fruit cultivars during cool-storage. Food Chemistry, Oxford, v. 63, n. 4, p. 529-534, 1998.

OLIVEIRA, M. A. de; SANTOS, C. H.; HENRIQUE, C. M.; DOMINGOS, J. R. D. Ceras para conservação pós colheita de frutos de abacateiro fuerte, armazenados em temperatura ambiente. Scientia Agricola, Piracicaba, v. 57, n. 4, p. 777-780, 2000.

PASTOR, C.; SÁNCHEZ-GONZÁLEZ, L.; CHÁFER, M.; CHIRALT, A.; GONZÁLEZ MARTÍNEZ, C. Physical and antifungal properties of hydroxypropylmethylcellulose based films containing própolis as affected by moisture content, Carbohydrate Polymers, Barking, v. 82, n. 4, p. 1174-1183, 2010.

PECH, J. C. Unravelling the mechanisms of fruit ripening and development of sensory quality thought the manipulation of ethylene biosynthesis in melon. In: NATO ADVANCED RESEARCH WORKSHOP ON BIOLOGY AND BIOTECHNOLOGY OF THE PLANT HORMONE ETHYLENE, 2002, Murcia. Anais... Murcia: [s.n.], 2002. 
SEYMOUR, G. B.; TUCKER, G. A. Avocado. In: SEYMOUR, G. B.; TAYLOR, J. E.; TUCKER, G. A. Biochemistry of fruit ripening. London: Chapman \& Hall, 1993. p. 53-76.

STATISTICAL ANALYSIS SYSTEM - SAS. SAS/STAT user's guide. version 6.12. 4. ed. Cary: 2003. v. 2, 842 p.
TRIPATHI, P.; DUBEY, N. K. Exploitation of natural products as an alternative strategy to control postharvest fungal rotting of fruit and vegetables. Postharvest Biology and Technology, Amsterdam, v. 31, n.3, p. 235245, 2004. 
